\title{
AS IMAGENS DA MODERNIDADE NOS “QUADROS \\ PARISIENSES" DE BAUDELAIRE E A RELAÇÃO COM O CADERNO “J-BAUDELAIRE” DO PROJETO DAS PASSAGENS
}

Jorge Benedito de Freitas Teodoro ${ }^{1}$

\begin{abstract}
RESUMO
O Projeto das Passagens do filósofo Walter Benjamin oferece um conjunto de ricas imagens sobre o advento da modernidade. Em sua maneira peculiar de escrita, Benjamin desvela o que se encontra por detrás destas imagens, isto é, a dura realidade do processo de produção. Entre as imagens com as quais Benjamin compõe um mosaico sobre a modernidade, escolhemos, para esta apresentação, a figura do poeta francês Charles Baudelaire. O poeta, para Benjamin, constitui o expoente máximo da modernidade, porque através de sua poesia, ele expõe, de maneira alegórica, a sociedade moderna. Desejamos mostrar como o filósofo destaca a capacidade de alegorização de Baudelaire com ênfase no conjunto de poemas "Quadros Parisienses", que integra As Flores do Mal. Desse modo, o presente artigo, como um recorte da pesquisa "As imagens da modernidade no Projeto das Passagens de Walter Benjamin", em realização no PPG de Estética e Filosofia da Arte da Universidade Federal de Ouro Preto (UFOP), tem como finalidade investigar o movimento alegórico desta interpenetração do antigo no moderno nos principais poemas a que Benjamim se refere no caderno "J-Baudelaire" do Projeto das Passagens.
\end{abstract}

Palavras-chaves: Benjamin. Baudelaire. Modernidade. Imagens. Alegoria.

\begin{abstract}
The Arcade Projects design of the philosopher Walter Benjamin offers a rich set of images on the advent of modernity. In his peculiar way of writing, Benjamin reveals what lies behind these images, that is, the harsh reality of the production process. Among the images with which Benjamin composed a mosaic of modernity, we chose for this presentation, the figure of the French poet Charles Baudelaire. The poet, for Benjamin, is the epitome of modernity, because through his poetry, he argues, allegorically, modern society. We hope to show how the philosopher highlights the ability of allegorization to Baudelaire with emphasis on the collection of poems "Parisian Tables," which integrate Flowers of Evil Thus, the present article, as part of a research "The images of modernity in the Arcade Projects of Walter Benjamin", in carrying out the PPG of Aesthetics and Philosophy of Art, Federal University of Ouro Preto (UFOP), aims to investigate the allegorical movement of this interpenetration of the antiquity in the modern poems that Benjamin refers in the notebook " $\mathrm{J}$ Baudelaire" of The Arcade Projects.
\end{abstract}

Keywords: Benjamin. Baudelaire. Modernity. Images. Allegory.

Jorge Benedito de Freitas Teodoro é Mestrando em Estética e Filosofia da Arte na

Universidade Federal de Ouro Preto. 
Neste breve artigo, propomos investigar as imagens que revelam as interseções entre antiguidade e modernidade, além das imagens carregadas de intenção alegórica, no segundo ciclo de poemas, intitulado "Quadros Parisienses", da obra As Flores do Mal, ${ }^{2}$ publicada por Baudelaire em 1857, destacando os poemas mais citados pelo filósofo Walter Benjamin no caderno "J-Baudelaire" do Projeto das Passagens (1927-1940). Para isso, recorreremos principalmente às interpretações realizadas pelo filósofo, atendo-nos aos fragmentos do caderno "J", e aos ensaios "Paris do Segundo Império" (1938) e "Sobre Alguns Temas em Baudelaire" (1939). Contaremos também com observações de demais comentadores.

Em os "Quadros Parisienses", segundo Benjamin, "Baudelaire não descreve nem a população, nem a cidade. Ao abrir mão de tais descrições colocou-se em condições de evocar uma na imagem outra"3. Essa evocação de uma imagem para dizer outra evidencia o procedimento alegórico adotado pelo poeta, uma vez que retoricamente tal procedimento "consiste na substituição do pensamento em causa por outro pensamento"4. No caso de Baudelaire, a substituição se daria de uma imagem "a", por outra imagem "b" que fosse capaz de substituir o sentido de "a" de maneira alegórica, ou seja, um movimento imagético entregue a interpretação em um jogo de significação que não pressupõe a identidade entre significado e significante. $O$ destaque acrescido ao caráter alegórico se dá, sobretudo, pela característica da modernidade constituir-se enquanto efêmera e transitória ${ }^{5}$, cujo signo determinante é a "novidade", de modo que, somente o jogo de significação alegórico daria conta de tentar acompanhar a constante volatilização da vida na metrópole moderna.

A cidade grande aparece na poesia baudelairiana, em especial nas alegorias dos "Quadros Parisienses", marcada sempre por seu caráter

\footnotetext{
${ }^{2}$ Utilizaremos nesse estudo a edição de As Flores do Mal publicada em 2006, pela editora Nova Fronteira, tradução de Ivan Junqueira.

3 BENJAMIN, 1989, p. 116.

4 LAUSBERG, 1976, apud HANSEN, 2006, p.07.

5 Trabalhamos com essa definição a partir da proposta por Baudelaire no ensaio "O Pintor da Vida Moderna" onde o poeta diz que "A modernidade é o transitório, o fugidio, o contingente, a metade da arte cuja outra metade é o eterno e o imutável." BAUDELAIRE, 2010, p.35.
} 
transitório efêmero revelado na "reurbanização" que expõe as relações entre a nova e a antiga Paris, conforme aponta Benjamin no fragmento [J 57a, 3]:

\begin{abstract}
Quando evoca Paris em seus versos, Baudelaire faz ressoar a decrepitude e a caducidade de uma cidade grande. Talvez seu mais perfeito exemplo esteja no "CrepúsculeduMatin" que a reprodução, a partir dos materiais da cidade, do soluçar o homem prestes a despertar. Este aspecto, porém, é mais ou menos comum a todo o ciclo de poemas dos "Tableaux Parisiens".
\end{abstract}

As transformações da cidade de Paris, realizadas pelo Barão de Haussmann, visando o "embelezamento estratégico" da cidade como forma de impedir a insurreição de populares em barricadas e melhorar o deslocamento das tropas de militares, apresentavam uma nova constituição da cidade devido à transformação das alamedas em boulevards, e a modificação arquitetônica da metrópole através da ampla utilização do ferro e vidro em suas construções. Esta reurbanização ao mesmo tempo em que apresentava uma nova "imagem" da metrópole parisiense, revelava a fachada de uma antiga Paris em ruínas, ao passo que essa nova "imagem" constituía-se através dessas mesmas ruínas, conforme evoca Benjamin no seguinte fragmento do Projeto das Passagens: "em Paris, a moradia moderna desenvolveu-se pouco a pouco a partir daquela já existente" ${ }^{\prime 7}$. Esse caráter transitório e relacional entre antigo e moderno revela-se com primazia no poema "O cisne".

"O cisne", poema que segundo Benjamin, "possui o movimento de um berço que balança entre a modernidade e a Antiguidade" ${ }^{8}$, é considerado pelo filósofo como grande expoente da alegoria em Baudelaire, justamente por expor a frágil constituição da cidade e dos habitantes de Paris, além de realizar com maestria a interpenetração entre antiguidade e modernidade. Segundo Luciano Gatti, no artigo "Experiência da Transitoriedade: Walter Benjamin e a Modernidade de Baudelaire", é possível "reconhecer a interpenetração mais íntima da modernidade com a antiguidade em poemas como "O cisne", tendo em vista que ambas "se cruzam pela marca do novo: é na transitoriedade que a modernidade se apresenta mais intimamente ligada a antiguidade."

\footnotetext{
[J 57a, 3] BENJAMIN, 2009, p. 378.

[E 14] BENJAMIN, 2009, p.187.

[J 72,5] BENJAMIN, 2009, p.402.

GATTI, 2009, p.165.
} 
A transitoriedade de Paris revela seus símbolos de fragilidade, presentes no poema na figura dos exilados - na alegoria de Andrômaca e do cisne dentro de um tempo regido pela produção de bens materiais que não permite a reflexão e a retomada da rememoração do passado. Nesse sentido, de acordo com Gatti,

[...] o exílio de Andrômaca pode ser lido como exílio de uma tradição histórica e literária que ela representa e que não pode ser acolhida no espaço da cidade. A mesma expulsão ocorre com o cisne. Ele indica tanto a expulsão da vida orgânica pelo processo de urbanização e transformação em concreto de todo o ambiente como uma alegoria de todos os exilados sem lugar na cidade. ${ }^{10}$

A modernidade, constituída sobre um tempo estruturado a fim da produção material e tendo o transitório como regulador de suas relações, assinala aos exilados que não existe lugar para eles em sua sociedade, para Benjamin, é "nessa debilidade" própria da época moderna que "por último e mais profundamente, a modernidade se alia à antiguidade. Sempre que aparece em As Flores do Mal, Paris carrega essa marca." ${ }^{11}$ Essa debilidade apresenta-se na oposição temporal entre o spleen- tempo que devora tudo e ao mesmo tempo é a força que trás o novo, transformando a novidade em antiguidade - e o ideal, tempo da rememoração que se instaura na figura dos exilados ao tentarem se lembrar de um tempo outro, de uma Paris antiga.

Gatti, ainda sobre a interpretação benjaminiana do poema "O cisne", aborda a potência alegórica contida no poema em sua segunda parte. Nessa abordagem - diferentemente daquela realizada na primeira parte do poemaem que o poeta olha melancolicamente o movimento de mudança da cidade de Paris -, Gatti afirma que "a alegoria, de que o poeta é consciente, é uma indicação do sentido de perda e alienação que se instaura entre o poeta e as imagens da cidade.." ${ }^{12} \mathrm{Na}$ construção alegórica contida nessa segunda parte, o poeta realiza a imobilização do movimento de interpenetração entre a velha e a nova Paris, para dar lugar à imagem de uma cidade em ruínas, revelando a cidade sob o olhar do exilado.

Outra imagem essencial, presente nos "Quadros Parisienses", fundada nesse cenário transitório da metrópole, é a figura do herói moderno que situa-

\footnotetext{
${ }^{10}$ GATTI, 2009, p. 168.

${ }^{11}$ BENJAMIN, 1989, p.81.

${ }^{12}$ GATTI, 2009, p. 168.
} 
se para Benjamin como "o verdadeiro objeto da modernidade."13 O filósofo berlinense sublinha que todas as figuras escolhidas pelo poeta para comporem a imagética do herói são aquelas que estão à margem do sistema de produção capitalista e que, justamente por isso, não participam dessa maquinaria. Heróis que têm como traço fundamental a necessidade material como sua experiência mais marcante, aos quais enquadram-se o poeta, o flâneur, o dândi, o salteador, a prostituta, a lésbica, o apache, o trapeiro, os velhos e os proletários.

Para Benjamin, a modernidade opõe ao processo criativo natural uma força de resistência desproporcional às forças do ser humano. Essa resistência sujeita o homem, enfraquecido pelas vicissitudes da vida moderna, a procurar refúgio na morte, por isso, o filósofo coloca a modernidade sob o signo do suicídio como uma vontade heroica capaz de renegar qualquer modo de pensamento que the é hostil. De acordo com o filósofo, o suicídio é "a conquista da modernidade no âmbito das paixões." ${ }^{14}$ Contudo, em Baudelaire, o suicídio aparece como "o único ato heroico que restara às populações doentias das cidades naqueles tempos reacionários." ${ }^{15}$ Uma paixão heróica que acometia os excluídos.

Essas populações heroicas e doentias são os objetos alegóricos principais de dois poemas dos "Quadros Parisienses", "Os sete velhos" e "As velhinhas". Nesses poemas, o cenário (as ruelas de Paris) e o herói (os excluídos) reúnem-se nas imagens decrépitas das figuras que, em seu estranho caminhar, percorrem a cidade. Essas figuras da decrepitude transformam-se em verdadeiros heróis modernos por resistirem, ainda que esfarrapados, ao tempo da modernidade que devora tudo em seu processo de produção. É possível destacar a condição heroica dessas populações na última estrofe do poema "As velhinhas", precisamente, na imagem construída por Baudelaire que retrata 0 ato de resistência das velhas senhoras ao apreciarem "o único e autêntico heroísmo ainda produzido por essa sociedade" ${ }^{16}$, isto é, a fanfarra formada por campesinos empobrecidos que se apresentam em um velho jardim:

\footnotetext{
${ }^{13}$ BENJAMIN, 1989, p. 73.

${ }^{14}$ BENJAMIN, 1989, p. 75.

${ }^{15}$ BENJAMIN, 1989, p. 75.

${ }^{16}$ BENJAMIN, 1989, p. 73.
} 
Outra, orgulhosa e tesa, atenta à melodia,

Sorvia avidamente esse coral guerreiro;

O olho, qual o de uma águia, às vezes se entreabria;

Tinha a marmórea fronte digna de um loureiro! ${ }^{17}$

A alegoria aparece nesses poemas em uma perspectiva capaz de conjugar decrepitude e rememoração na imagem dos velhos, como aponta Benjamin no fragmento [J 71,2], que revela a potência de resistência ao tempo devorador ao descrever às imagens dos ancestrais decrépitos como "receptáculos inesgotáveis de recordações." 18 Os velhos que em sua decrepitude percorrem a cidade em um estranho caminhar, encurvados de espinha quebrada, enfermos, senis, enrugados, dotados de um ar fantasmagórico, carregam, dentre outras coisa, a imagem do grotesco na poesia baudelairiana ${ }^{19}$. Segundo Luiz Costa Lima (1980), em Mimesis e Modernidade, "o grotesco baudelairiano está sempre relacionado ao grande número de figuras macabras, sejam moscas, fossos, vazios criados no corpo, deformação de seus membros." ${ }^{20}$ Nada mais condizente com a citação de Costa Lima do que a fisionomia do primeiro velho do poema "Os sete velhos":

\footnotetext{
Não era curvo, mas quebrado, e sua espinha Compunha com a perna um claro ângulo reto, Tanto mais que o bastão, que a seu perfil convinha, Lhe dava o ar retorcido e o ímpeto incorreto. ${ }^{21}$
}

A metrópole que abriga os símbolos do exílio e reserva espaço para a resistência do herói moderno, oferece ao poeta, como um material fértil para sua poesia, a figura da multidão. É, justamente, em seu encontro com a multidão que Baudelaire se confronta com a experiência do choque ao travar combate pela presa poética. $O$ poeta é um fascinado pela multidão. Nela, ele encontra o choque de um olhar que o desperta para o amor, como em "A uma passante", poema construído como uma grande alegoria sobre a multidão, contudo, a temática principal do poema não é sequer mencionada. A imagem

\footnotetext{
${ }^{17}$ BAUDELAIRE, 2006, p.315.

${ }^{18}$ BENJAMIN, 2009, p. 400.

${ }^{19}$ É importante ressaltar que a característica do grotesco na poesia baudelairiana não reside apenas nas imagens dos velhos, depositas nos poemas "As velhinhas" e "Os sete velhos", como também em outros diversos poemas da lírica de Baudelaire, como por exemplo, nos poemas "Uma carniça" e "O frasco".

${ }^{20}$ COSTA LIMA, 1980, p. 127.

${ }^{21}$ BAUDELAIRE, 2006, p. 307.
} 
da multidão, em "A uma passante", repousa no "véu agitado através do qual Baudelaire via Paris." 22 A passante, descrita como uma viúva encoberta por um traje lutuoso que carrega sua dor arrastada pela multidão, ao trocar olhares transitórios com o poeta, revela-nos que o objeto de fascinação do habitante da metrópole moderna é a própria multidão. Bernardo B. C. de Oliveira, no artigo "Baudelaire, Benjamin e a arquitetura D'As Flores do Mal', considera o poema "A uma passante" como uma chave na interpretação realizada por Benjamin acerca da obra de Baudelaire. De modo que, o poema está intrinsecamente relacionado com a perda da experiência autêntica (Erfahrung) e sua substituição por uma experiência pautada no choque com a multidão, apresentada como uma vivência (Erlebnis) típica do sujeito moderno. Como experiência autêntica, podemos entender aquela experiência transmitida em sentido pleno, compartilhada de maneira coletiva e socialmente. A vivência é a substituta da Erfahrung, de modo que se constitui como experiência determinante da sociedade capitalista, onde a vida do sujeito é normatizada e determinada pelos meios de produção.

O sujeito no mundo moderno, determinado pelo processo de produção e pelo tempo reificado, encontra-se impossibilitado de desenvolver uma experiência autêntica, pois todas as experiências contidas nessa sociedade resumem-se às adquiridas na vivência diária do contato com a máquina e nos choques com a multidão. É, de acordo com Benjamin, uma "experiência inóspita." ${ }^{23} \mathrm{O}$ destaque atribuído ao poema "A uma passante" em sua relação com a experiência é relevante, segundo Oliveira, pois "sugere uma situação perceptiva ainda não inteiramente fragmentada, ou antes, trata-se de um fragmento que ainda guarda um fiapo de lembrança do todo do qual um dia, talvez, tenha feito parte." ${ }^{24}$ Sendo assim, o poema situa-se entre a experiência totalmente fragmentada da metrópole moderna e a rememoração da ligação experiencial com a totalidade anterior, pela potencialidade de resguardar uma correspondência com a experiência autêntica depositada no emblema do traje lutuoso que envolve a passante. Oliveira aproxima a significação do luto, destacado no emblema do véu, ao desenvolvimento realizado por Benjamin em

\footnotetext{
${ }^{22}$ BENJAMIN, 1989, p. 117.

${ }^{23}$ BENJAMIN,1989, p. 105.

${ }^{24}$ OLIVEIRA, 2007, p. 223.
} 
Afinidades Eletivas de Goethe, onde o filósofo berlinense afirma que "em tudo o mais, a aparência pode enganar, mas a bela aparência é o véu estendido diante disto que exige, mais do que tudo, ser velado. Pois o belo não é nem o véu nem o velado, mas o objeto sem véu." 25

Nesse sentido, o véu da passante possui uma forte correspondência com a bela aparência que, por sua condição velada e indecifrável, mantém seu caráter distante, impossível de se relacionar com a percepção do homem moderno. A experiência do poeta que "troca olhares" com aquela que passa significa, para Oliveira, uma "experiência perceptiva que consiste em captar o mistério ou a irrepetibilidade irremissível dos fenômenos" ${ }^{\text {"26 }}$, constituindo-se extremamente diferente da vivência experienciada pelo transeunte moderno. Essa relação confere ao poema um caráter dualista no que toca à experiência na poética baudelairiana, pois, ao mesmo tempo em que se refere ao choque como mediador das relações do poeta com a multidão, concentra em um emblema alegórico a potência de se corresponder com a rememoração de uma experiência autêntica, vivida em tempos anteriores.

Restam-nos, ainda, apontar as imagens alegóricas que propiciam a relação entre antiguidade e modernidade nos dois poemas crepusculares dos "Quadros Parisienses", "O crepúsculo vespertino" e "O crepúsculo matinal". Inicialmente, Benjamin relaciona "O crepúsculo vespertino" com as iluminações que surgiam na nova metrópole e apontaram para um crescimento na segurança das ruas, fato que despertava na multidão o sentimento de que mesmo nas ruas ainda encontravam-se acalentadas, como nos interiores de suas residências. Parao filósofo, a nova iluminação "removeu do cenário grande o céu estrelado"27, colocação aproximada do verso baudelairiano: "Qual grande alcova o céu se fecha lentamente"28. Essa constatação da modernização técnica das iluminações das ruas de Paris remete-se ao movimento de superação da engenhosidade humana sobre a natureza, de modo que, na visão de Benjamin, o homem moderno, com os avanços da iluminação artificial, retirou a dignidade da Lua e das estrelas e, a seu modo,

\footnotetext{
${ }^{25}$ BENJAMIN, 1974, apud OLIVEIRA, 2007, p. 224.

${ }^{26}$ OLIVEIRA, 2007, p. 225.

${ }^{27}$ BENJAMIN, 1989, p.47.

${ }^{28}$ BAUDELAIRE, 2006, p. 323.
} 
sentenciou o habitante da cidade grande ao desconhecimento de "um verdadeiro crepúsculo da tarde"29.

"O crepúsculo vespertino" relaciona a segurança advinda da iluminação a gás com a confusão da multidão, representada pelos assassinos, operários e, principalmente pelos "demônios insepultos no ócio"30 figurados como homens de negócio, sujeitos desesperados, isolados em seus interesses privados. No fragmento [J 81,6], Benjamin aponta a falta de consistência na abordagem alegórica realizada por Baudelaire no verso supracitado, pelo fato do poeta deixar-se dominar pela alegoria, algo que não permite a sua alegorização de forma direta, mas sim distanciada. Porém, o gesto de distanciamento entre poeta e alegoria, segundo Benjamin, é justamente o que permite integrar a alegoria às "realidades mais imediatas." ${ }^{31}$ Nesse sentido, é esse gesto de distanciamento que permite Baudelaire abordar, através da intenção alegórica, os pormenores de uma realidade que se funda na lógica da produção materialonde o sujeito segue aos choques o destino cruel de ser devorado por um tempo do spleen.

O outro poema crepuscular de Baudelaire que fecha o ciclo de poemas "Quadros Parisienses", "O crepúsculo matinal”, é o mais citado por Benjamin no caderno "J" do Projeto das Passagens. Segundo o filósofo, "O poema 'Le crepúsculedumatin' [...] ocupa uma posição-chave. O vento matinal expulsa as nuvens do mito. O olhar sobre os homens e como eles agem está livre."32 A partir dessa citação, podemos estabelecer uma ligação com o poema investigado anteriormente, "O crepúsculo vespertino", no qual a noite havia se instaurado como um sonho mítico regido pela lógica do capital, no sentido próximo de uma segunda natureza, é expulsa pelo vento matinal, que por um breve momento desfaz as ilusões trazidas pela noite e instaura a luz do sol ao revelar a "nódoa vermelha" ${ }^{33}$ pertencente as luzes noturnas. Contudo, "O crepúsculo matinal" desfaz o sonho mítico da noite e, no seu lugar, coloca outro. É nele que Benjamin identifica o "cânone da passagem" ao determinar o movimento do poema, em cada uma de suas nove estrofes de dois versos,

\footnotetext{
${ }^{29}$ [J 64, 4] BENJAMIN, 2009, p. 388.

${ }^{30}$ BAUDELAIRE, 2006, p. 325.

${ }^{31}$ [J 81,6] BENJAMIN, 2009, p.416.

32 [J 22, 4] BENJAMIN, 2009, p. 313.

${ }^{33}$ BAUDELAIRE, 2006, p. 345.
} 
como alegorias de uma exposição em vitrine, no qual cada uma das estrofes revela a "imagem nítida de uma miséria nua e crua" ${ }^{34}$, como podemos visualizar no sexto dístico do poema: "As prostitutas, sob as pálpebras sem viço, / Boca aberta, dormiam seu sono maciço;"”35.

O sono ao qual se entrega a prostituta é o mesmo sono do progresso que envolve o imaginário do século XIX. É o sono de quem se entrega ao mercado sem hesitar, daquele que não enxerga o duro processo de produção por trás das mercadorias expostas na vitrine. A prostituta encarna em si a aparência da mercadoria, constituindo, por isso, a alegoria por excelência da modernidade, ao significar "a extensão máxima que a mercadoria pode alcançar." ${ }^{36}$ Os personagens e as imagens suscitadas em ambos os poemas "crepusculares" constatam a interpretação benjaminiana de que no ciclo de poemas "Quadros Parisienses" os traços da transitoriedade e da caducidade referentes à grande metrópole são os determinantes das interpenetrações entre a antiguidade e modernidade, de modo que é justamente nas imagens da caducidade da metrópole que essas duas temporalidades aliam-se mais profundamente.

\footnotetext{
${ }^{34}$ [J 88a, 2] BENJAMIN, 2009, p. 426.

${ }^{35}$ BAUDELAIRE, 2006, p. 345.

${ }^{36}$ [J 67a, 1] BENJAMIN, 2009, p. 393.
} 


\section{BIBLIOGRAFIA}

BAUDELAIRE, Charles. Quadros Parisienses. In:As Flores do Mal. Rio de Janeiro. Nova Fronteira, 2006.

BENJAMIN, Walter. J - Baudelaire. In:Passagens. Belo Horizonte: ED. UFMG, 2009.

. E - Haussmannização, Luta de Barricadas. In:Passagens. Belo Horizonte: ED. UFMG, 2009.

Paris do Segundo Império. In:Obras Escolhidas III. Charles Baudelaire, um lírico no auge do capitalismo. São Paulo: Ed. Brasiliense, 1989.

Sobre Alguns Temas em Baudelaire. In:Obras Escolhidas III.

Charles Baudelaire, um lírico no auge do capitalismo. São Paulo: Ed. Brasiliense, 1989.

COSTA LIMA, Luiz. Paris ante o olhar baudelairiano. In:Mímesis e Modernidade: formas das sombras. Rio de Janeiro. Edições Graal, 1980.

GATTI, Luciano. Experiência da Transitoriedade: Walter Benjamin e a Modernidade de Baudelaire. In:Revista Kriterion, vol. 119, p.159-178. Belo Horizonte,jun. 2009.

HANSEN, João Adolfo. Alegoria, Construção e Interpretação da Metáfora. Campinas: Ed. da Unicamp, 2006.

OLIVEIRA, B. B. C. Baudelaire, Benjamin e a Arquitetura D' As Flores do Mal. In: Revista ALEA, vol. 9, n.2, p. 48-63. Rio de Janeiro, jul.-dez. 2007. 